\title{
Adapting complex multi-level landscape systems to climate change
}

\author{
Eric Koomen • Paul Opdam • Eveliene Steingröver
}

Received: 25 January 2012/ Accepted: 1 February 2012/Published online: 24 February 2012

(C) The Author(s) 2012. This article is published with open access at Springerlink.com

\begin{abstract}
Adaptation to climate change is becoming a prominent issue in both landscape research and landuse planning. Current research focuses mainly on the description of potential impacts for different societal sectors and in general fails to provide useful information to help define climate adaptation strategies and specific policy measures or development plans. This editorial briefly explores the reasons why this may be the case and proposes a conceptual framework for more effective climate adaptation research. Furthermore, it introduces three papers that address adaptation of landscape systems to climate change as an integrated multi-level challenge. The included papers focus on the relationship between climate-induced changes in the natural system and the economicsoriented societal system and specifically address the interdependencies across scales.
\end{abstract}

\footnotetext{
E. Koomen $(\square)$

Faculty of Economics and Business Administration, VU University Amsterdam, De Boelelaan 1105, 1081 HV Amsterdam, The Netherlands e-mail: e.koomen@vu.nl

P. Opdam · E. Steingröver

Landscape Centre, Alterra Wageningen

UR, Droevendaalse Steeg 3, 6708 PB Wageningen,

The Netherlands

P. Opdam

Land Use Planning Group, Wageningen University, Droevendaalse Steeg 3, 6708 PB Wageningen,

The Netherlands
}

Keywords Climate change Climate adaptation . Landscape systems $\cdot$ Multi-level approach

Temperature increase, changing precipitation patterns and more severe weather extremes, as predicted during climate change, have a wide impact on ecological processes in landscapes. People respond to these changes by considering to adapt land use and spatial structure of landscapes. Flood protection measures, for example, require more space in low-lying coastal regions and along rivers where flooding is likely to become more frequent (Aerts et al. 2011). Adaptation measures are also appropriate in upstream parts of river catchments to increase the potential of the landscape for water retention (Begum et al. 2007). Climate change may also affect agricultural systems through water shortages, higher temperatures and salinization (Olesen et al. 2002; Reidsma et al. 2009). Climate change impacts on biodiversity call for larger protected areas, enhanced spatial heterogeneity and more connectivity (Vos et al. 2008; Mawdsley et al. 2009). Such adaptation measures, which often demand more space for sectorial aims, have to be realized in an era with expanding urban populations that claim more space for residences, employment and recreation, whilst simultaneously attributing great value to ecosystem and landscape services associated with agricultural and natural landscapes (Van der Heide and Heijman 2012). This extensive set of competing spatial claims causes land-use conflicts, but also 
creates opportunities for landscape redevelopment. However, creating a common vision on how landscapes could spatially be adapted to cope with climate change is a complex challenge. This is not only due to the many different views on the nature and urgency of the problems among stakeholders, but also due to the high degree of uncertainty in future climatic and societal conditions and poorly understood feedbacks between these systems.

\section{Climate adaptation research}

While climate change is a global phenomenon with regionally variable patterns, adaptation is implemented at the local scale, as part of current land development plans (Tompkins et al. 2010; Preston et al. 2011). In searching for opportunities to create synergies between economically or environmentally driven land-use change and climate-proofing needs, actors involved in local spatial planning need a clear view on the ecological, economic and societal values that are impacted by changing climatic conditions. Such potential impacts have been described for many sectors separately, but these descriptions only offered a small contribution to the definition of climate adaptation strategies and specific policy measures or development plans (Preston et al. 2011). This failure of science to provide useful information may partly be due to: 1) the predominantly technological approaches and science-driven modelling that poorly match the societal context of land development; 2) the sectorspecific focus neglecting effects of adaptation measures to other land use sectors; and 3) the large level of scale that is not recognized as relevant by local stakeholders. We strongly believe that climate adaptation research can only be relevant to actual planning and development when it: 1) applies a decision makers focus on the analysis of impacts, the presentation of results and suggestion of alternative strategies; 2) offers an integrated view on the landscape system and the changes it faces in climatic conditions, biophysical and socio-economic processes; and 3) addresses multiple scale levels (both in the social and the physical system) and the links between them. Figure 1 illustrates this conceptual framework: in order to develop climate adaptation measures a decision maker should receive information on how changes in climatic conditions affect the bio-physical and socio-economic processes that comprise the landscape system. This assessment of changes in the landscape system should incorporate the relationships between different processes, acknowledge that processes act differently at different scale levels and address cross-scale linkages.

\section{Layout special section}

This special section contains research presented at the Deltas in Times of Climate Change conference in September 2010 in Rotterdam, The Netherlands. It addresses adaptation of landscape systems to climate change as an integrated multi-level challenge. The relationship between climate-induced changes in the natural system and the economics-oriented societal system is put central. All studies have in common that they specifically address the interdependencies across scales, yet their geographic and policy context is different. Subsequently, the following issues come along: informing about scale interactions for multilevel governance; informing about trade-offs in a multi-level context; scale global insights down to local level where landowners make decisions (an example of farms); and interactive visualisation tools to support the design of solutions at the local level.

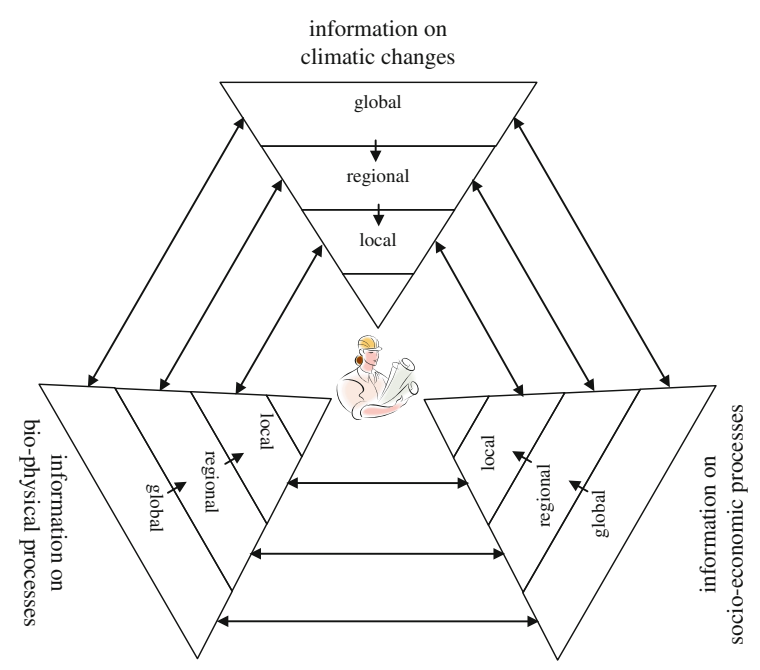

Fig. 1 Climate adaptation research should: (1) put the decision maker central; (2) offer an integrated view on the landscape system and the changes in its constituting components (climatic conditions, bio-physical and socio-economic processes); and (3) address links between levels 
Verburg and others (2012) explore how European Union policy alternatives may affect flood risk, carbon sequestration, habitat connectivity and biodiversity at the local level in the 27 member states of the European Union. Their integrated analysis is able to assess synergies and trade-offs between different policy ambitions. It emphasizes that large scale policy may have very different implications at the local level resulting from the strong local variation in the land-use patterns. This modelling framework is particularly useful for supranational authorities and currently in use by the European Commission.

The work of Pettit and others (2012) highlights the importance of presenting information in a way that enhances collaborative processes of understanding and framing the problem resulting from climate change. Their work is relevant to decision makers, planners and communities at a range of scales and stages in the planning cycle. They present the initial development of a multi-scale visualisation toolkit for use in climate change response that was applied in Australia at scales ranging from global to local. Their local work, for example, explores adaptation options for local dairy farmers in south west Victoria.

Mandryk and colleagues (2012) have developed scenarios of farm structural change for application in climate change assessments. Starting from global and European scenarios of climate change and considering changes in other societal driving forces as well they quantitatively characterise typical future farms in the Flevoland region of The Netherlands. Their approach relies on the input of local stakeholders (e.g. farmers and local policy makers) and the resulting sketches of potential future farm characteristics can help them prepare for upcoming climatic and other changes.

Acknowledgments We are grateful to the Dutch National research programme 'Climate Changes Spatial Planning' for sponsoring the work involved in organising this special issue. Furthermore, we like to thank the organising committee of the 'Deltas in Times of Climate Change' conference for allowing us to host the 'Competing claims and land use' and 'Decision support instruments for climate adaptation policy' sessions. This occasion provided the inspiration and content for this special section. Last, but not least, we are particularly grateful to the authors and reviewers for contributing their papers and valuable comments.

Open Access This article is distributed under the terms of the Creative Commons Attribution License which permits any use, distribution, and reproduction in any medium, provided the original author(s) and the source are credited.

\section{References}

Aerts J, Botzen W, Bowman MJ, Ward PJ, Dircke P (eds) (2011) Climate Adaptation and flood risk in coastal cities. Earthscan, Oxford/New York

Begum S, Stive MJF, Hall JW (eds) (2007) Flood Risk Management in Europe. Innovation in Policy and Practice. Advances in Natural and Technological Hazards Research, vol. 25

Mandryk M, Reidsma P, Van Ittersum M (2012) Scenarios of long-term farm structural change for application in climate change assessments. Landscape Ecol

Mawdsley J, O’Malley R, Ojima DS (2009) A review of climate change adaptation strategies for wildlife management and biodiversity conservation. Conserv Biol 23:1080-1089

Olesen JE, Bindi M (2002) Consequences of climate change for European agricultural productivity, land use and policy. Eur J of Agron 16(4):239-262

Pettit C, Bishop I, Sposito V, Aurambout J-P, Shethl F (2012) Developing a multi-scale visualisation toolkit for use in climate change response. Landscape Ecol

Preston BL, Westaway RM, Yuen EJ (2011) Climate adaptation planning in practice: an evaluation of adaptation plans from three developed countries. Mitig Adapt Strateg Glob Change 16:407-438

Reidsma P, Ewert F, Oude Lansink A, Leemans R (2009) Vulnerability and adaptation of European farmers: a multilevel analysis of yield and income responses to climate variability. Reg Environ Change 9(1):25-40

Tompkins EL, Adger WN, Boyd E, Nicholson-Cole S, Weatherhead K, Arnell N (2010) Observed adaptation to climate change: UK evidence of transition to a well-adapting society. Glob Environ Change 20:627-635

Van der Heide M, Heijman W (eds) (2012) The Value of Landscapes. Essays on Landscape Economics, Routeledge (forthcoming)

Verburg, PH, Koomen E, Hilferink M, Perez-Soba M (2012) An assessment of the impact of climate adaptation measures to reduce flood risk. Landscape Ecol

Vos C, Berry P, Opdam P, Baveco H, Nijhof B, O'Hanley J, Bell C, Kuipers H (2008) Adapting landscapes to climate change: examples of climate-proof ecosystem networks and priority adaptation zones. J Appl Ecol 45:1722-1731 